\title{
Alterações hidrogeomorfológicas devido à dinâmica de uso da terra na Bacia Hidrográfica do Ribeirão Santa Gertrudes (SP)
}

\author{
Letícia Giuliana Paschoal ${ }^{1 *}$, Fabiano Tomazini da Conceição ${ }^{1}$, Cenira Maria Lupinacci da Cunha ${ }^{1}$
}

\begin{abstract}
Resumo Atividades agrícolas e de mineração a céu aberto estão diretamente relacionadas à alteração das paisagens naturais. Esta pesquisa se desenvolveu por meio da perspectiva da geomorfologia antropogênica amparada pela teoria geral dos sistemas, com o objetivo de identificar e analisar as alterações ocorridas no uso da terra, provenientes, principalmente, da atividade agrícola e da explotação da argila, e suas implicações nas características hidrogeomorfológicas na bacia hidrográfica do Ribeirão Santa Gertrudes (SP). Esta área insere-se no contexto do Pólo Cerâmico de Santa Gertrudes (SP), que além de sua importância como fornecedora de matéria-prima, configura-se como o maior centro de referência internacional em pavimentos cerâmicos do continente americano. Para isso, foram geradas cartas de uso da terra e geomorfológicos de dois cenários, correspondentes aos anos de 1962 e 2006, os quais permitiram a identificação das alterações causadas pelas ações antrópicas sobre as formas de relevo da área, como é o caso do aumento em área de parcelas destinadas à atividade minerária, que de 3,1\% passou a ocupar 19\% da área da bacia hidrográfica no respectivo período e que, dentre outras alterações, deu origem a novas formas de relevo, como, por exemplo, os patamares em cava de mineração abruptos e suaves. Os resultados indicam que as principais feições representativas da alteração humana no relevo são representadas pela abertura de grandes cavas de mineração de argila e as atividades agrícolas, as quais intensificaram os processos denudativos e de sedimentação na bacia hidrográfica do Ribeirão Santa Gertrudes.
\end{abstract}

Palavras-chave: geomorfologia antropogênica; uso da terra; cartografia geomorfológica; Ribeirão Santa Gertrudes.

\begin{abstract}
Hydro-geomorphological changes due to dynamics of land use in the Santa Gertrudes Stream Watershed $(S P)$. Agricultural and mining activities are directly related to changes in natural landscapes. From the perspective of anthropogenic geomorphology supported by general systems theory, this research has developed, in order to identify and analyze changes in the land use, mainly from agriculture and the exploitation of clay, and its implications in the hydro-geomorphological characteristics in the Santa Gertrudes Stream watershed (SP). This area is within the context of the Ceramic Pole Santa Gertrudes (SP), which besides its importance as a supplier of raw material, is characterized as the largest center of international reference in ceramic tiles on the American continent. For this purpose, we made land use and geomorphology maps of two scenarios, corresponding to the years 1962 and 2006, which allowed the identification of changes caused by human activities on the landforms of the area, such as the increase in area of parcels intended for mining activity, which went from $3.1 \%$ to occupy $19 \%$ of the catchment area of the respective period and that, among other changes, gave rise to new forms of relief as, for example, in levels of pit mining abrupt and smooth. The results indicate that the main features of representative of human changes in relief are represented for opening of large clay mining pits and agricultural activities, which intensified the denudation and sedimentation processes in the Santa Gertrudes Stream watershed.
\end{abstract}

Keywords: anthropogenic geomorphology; land use; geomorphological mapping; Santa Gertrudes Stream.

\section{INTRODUÇÃO Como decorrência do con-} sumo exacerbado, o poder de resiliência dos sistemas ambientais físicos são extrapolados, e inúmeras transformações nas camadas (sub)superficiais da crosta terrestre e, consequentemente, na paisagem têm origem. Esta situação foi passível de análise a partir do estudo de caso da bacia hidrográfica do Ribeirão de Santa Gertrudes (Fig. 1), situada no interior do estado de São Paulo, na qual o sistema antrópico, por meio do uso da terra, destinado predominantemente a cultivos agrícolas e, posteriormente, atividades minerárias por meio da explotação de argila, impôs novos mecanismos de controle aos sistemas ambientais físicos.

A área total da bacia do Ribeirão Santa Gertrudes é de $27,87 \mathrm{~km}^{2}$, estando inserida dentro dos limites do município de Santa Gertrudes (SP). As unidades geológicas que afloram correspondem às formações Corumbataí e Serra Geral, como ilustrado na Fig. 1. A Formação Serra Geral situa-se por todo o rebordo Leste, Noroeste, Norte e Nordeste da área de estudo, sendo formada por rochas intrusivas 


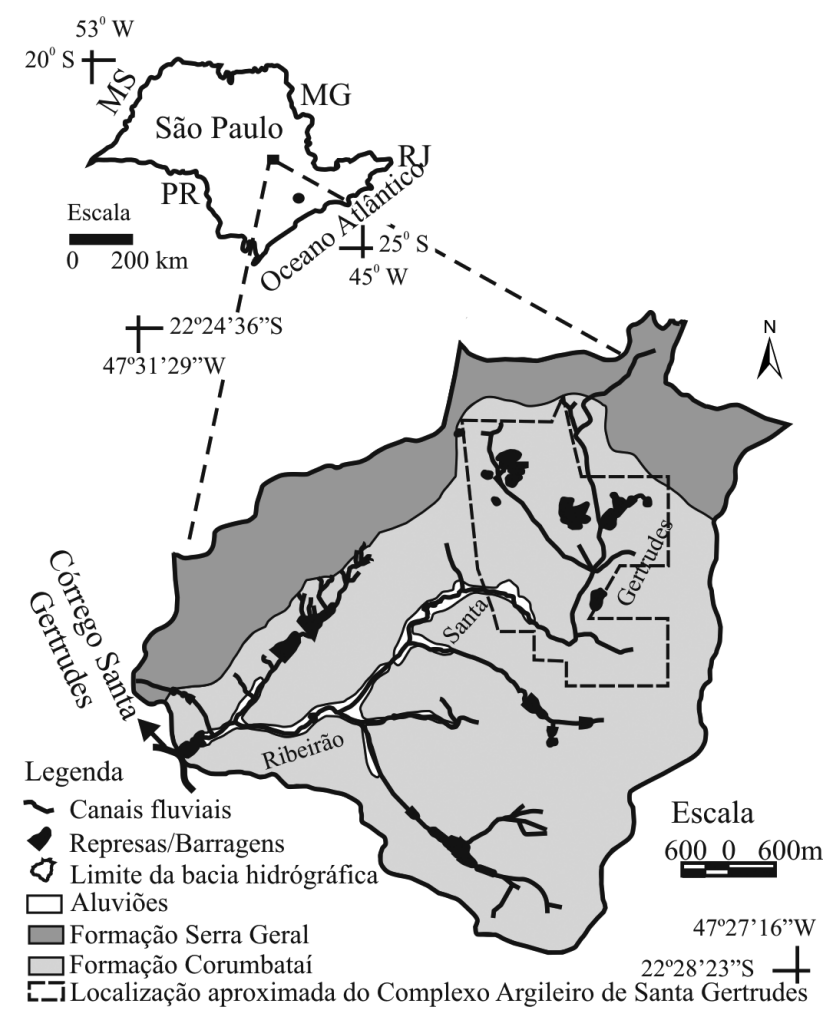

Figura 1 - Localização da bacia hidrográfica do Ribeirão Santa Gertrudes no estado de São Paulo e as unidades geológicas que afloram em seu interior.

básicas. A Formação Corumbataí preenche a área restante da bacia e corresponde a siltitos, folhelhos e argilitos com intercalação de camadas carbonáticas e coquinas. Os aluviões estão presentes em alguns trechos que margeiam, principalmente, o baixo curso do Ribeirão Santa Gertrudes, tratando-se de areias e argilas inconsolidadas com granulações variáveis.

O afloramento da Formação Corumbataí na área propicia a explotação da matéria-prima utilizada pelas indústrias cerâmicas do Pólo Cerâmico de Santa Gertrudes (SP). Pólo, esse, formado por oito municípios, nos quais, Santa Gertrudes, Cordeirópolis, Rio Claro, Limeira, Ipeúna, Araras e Piracicaba, concentram 45 empresas do setor, sendo elas responsáveis por $56 \%$ da produção brasileira, o que equivale a uma produção de cerca de 423 milhões de $\mathrm{m}^{2}$ de revestimento cerâmico por ano (BNDES 2006, ASPACER 2010). E é nesses mesmos municípios mais o de Charqueada, com excessão de Piracicaba e Araras, que concentram-se as áreas onde são explotadas as argilas que abastecem o Pólo (EIA 2008). Com relação à situação de explotação dessas minas, Gaspar Júnior (2003) afirmou que essas deveriam ser melhor gerenciadas, para se evitar o esgotamento precoce desse recurso mineral, estimando-se um tempo de vida útil de 14 anos para as minas em atuação no ano de 2003.

Desde o ano de 2004, a bacia hidrográfica do Ribeirão Santa Gertrudes, que já foi amplamente explotada e ainda possui um grande potencial para a extração de argila, está com parte de sua lavra paralisada devido a problemas com questões ambientais. Essa área corresponde a uma parcela da terra denominada Complexo Argileiro de Santa Gertrudes (Fig. 1), que soma 8 empreendimentos com 16 processos junto ao Departamento Nacional de Produção Mineral (DNPM), que juntas já atingiram o pico de $340.900 \mathrm{~m}^{3}$ de extração mensal de argila de suas minas (EIA 2008). Esse Complexo conta com 36,5 hectares de área e busca, a partir da aprovação de um Estudo de Impactos Ambientais e Relatório de Impacto Ambiental (EIA/RIMA), o qual vem sendo avaliado pelos órgãos competentes, um parecer favorável à continuação e expansão das áreas a serem lavradas (Reis 2009).

Assim, a grande escala de explotação dos recursos minerais na bacia hidrográfica do Ribeirão Santa Gertrudes, que nem sempre ocorre de forma planejada e ambientalmente sustentável, associado a áreas de cultivo de gêneros agrícolas, no qual se destaca a cana-de-açúcar, provocou uma série de impactos ambientais na área de estudo, que é definido pelo Conselho Nacional do Meio Ambiente, como qualquer alteração das propriedades físicas, químicas e biológicas do meio ambiente, causada por matéria ou energia resultante das atividades humanas que, direta ou indiretamente, afetam a saúde, a segurança e o bem-estar da população; as atividades sociais e econômicas; a biota; as condições estéticas e sanitárias do meio ambiente; e a qualidade dos recursos ambientais (Brasil 2008).

A extração desordenada da argila por um longo período de tempo causou impactos nos meios físicos, bióticos e socioeconômicos. Realizada a céu aberto, Christofoletti (1999a, p. 2) salienta que a lavra da argila era realizada geralmente "[...] sem qualquer planejamento, o que provoca a degradação de importantes depósitos e, consequente, desconfiguração da paisagem, que às vezes, termina em verdadeiras formações lacustres". Outras consequências relacionadas às alterações em áreas de atividade ceramista vinculada ao Pólo Cerâmico de Santa Gertrudes, em conjunto com atividades agrícolas, compreendem: dinamização dos processos erosivos no solo, processos de assoreamento dos cursos d'água, aumento da 
turbidez das águas superficiais, alteração das propriedades do solo e da qualidade das águas subterrâneas e superficiais, redução da disponibilidade hídrica subterrânea com redução da vazão dos corpos hídricos superficiais, diminuição da riqueza de espécies e perda da variabilidade genética, perda de habitat para a fauna terrestre, proliferação de vetores de doenças de veiculação hídrica, alteração na qualidade do ar devido ao aumento da emissão de poeira, entre outros (EIA 2008).

Relacionado aos aspectos socioeconômicos, é possível afirmar que a atividade de mineração da argila provoca impactos tanto negativos, quanto positivos. A população, principalmente a que reside muito próxima aos pátios de beneficiamento e às indústrias cerâmicas, sofre com a emissão de poeiras e com a turbidez das águas, que nem sempre está própria para o consumo e, em alguns períodos do ano, chega a fal$\operatorname{tar}$ (Levighin 2005, p. 4). Porém, é inegável que tal atividade econômica tenha dinamizado a economia regional, aumentado a receita dos municípios envolvidos e gerado emprego e renda para as famílias da região de formas direta e indireta. Além disso, esse pólo atingiu a marca de maior e mais importante Pólo Cerâmico das Américas, consagrando-se em um centro de referência internacional em pavimentos cerâmicos, o que torna sua relevância indiscutível para o desenvolvimento socioeconômico da região.

Diante desse cenário, a pesquisa desenvolvida e relatada neste artigo teve como objetivo identificar e analisar as alterações hidrogeomorfológicas na bacia hidrográfica do Ribeirão Santa Gertrudes, relacionadas ao uso da terra, provenientes do cultivo de gêneros agrícolas e da atividade de explotação da argila.

Para tanto, o desenvolvimento deste trabalho encontrou respaldo na Teoria Geral dos Sistemas com ênfase à antropogeomorfologia, a qual defende que a atividade do homem, integrada a fatores naturais, é responsável pelo esculpimento da paisagem (Nir 1983). Discussões como essa, relacionadas à temática ambiental, começam a ser publicadas e ganham ampla aceitação da comunidade científica apenas a partir da segunda metade do século XX, pois, até então, o interesse da geomorfologia pautava-se no entendimento das estruturas do relevo (Goudie 1993). A partir desse período, diversos trabalhos nacionais e internacionais, de âmbito teórico e prático, têm apresentado contribuições significativas a cerca dos controles que os sistemas socioeconômicos causam sobre os atributos dos sistemas físicos, podendo-se citar as obras de Nir (1983), Goudie (1986, 1993), Drew (1989), Haff (2001) e Rodrigues (1997, 2005), como norteadoras para o estudo das implicações das ações humanas sobre o meio físico.

Outros trabalhos de ordem mais prática, desenvolvidas dentro do âmbito da antropogeomorfologia e veiculados por periódicos de destaque no meio acadêmico, são os de Jean-Pierre (2004), Hooke (2006), Vieira \& Cunha (2008) e Brousse et al. (2011), que associam a temática a alterações hidrogeomorfológicas e uso da terra, bem como Simon \& Cunha (2008) e Perez Filho \& Quaresma (2011) que as aplicam à análises em bacias hidrográficas. Rodrigues (2005), Pellogia (2005) e Fujimoto (2005) pautam-se nas transformações vinculadas ao meio urbano. Gill (1996) e Corrêa (2011) desenvolvem suas pesquisas vinculadas a ambientes áridos e semiáridos e Lentz \& Hapke (2011) a aplica à análise de sistemas dunários em zonas costeiras. Outros trabalhos podem ser identificados ao serem aplicados a áreas de riscos provocados pela ação antrópica em áreas montanhosas (Remondo et al. 2005); ocupação em região deltaica (Banna et al. 2009) e em área de mineração inserida em meio urbano (Lóczy \& Gyenizse 2010).

Assim, recorreu-se às técnicas da cartografia temática para a elaboração de cartas de uso da terra e geomorfológicas evolutivas, em cenários relativos aos anos de 1962 e 2006, na escala de detalhe $1: 10.000$.

A elaboração destas cartas permite inferir a dinâmica do sistema em questão e procura retratar a paisagem e as feições geomorfológicas da área em um cenário de pré-intervenção (1962), anterior à explotação de grandes quantidades de argila, e um cenário representativo de uma fase de perturbação ativa (2006). A morfologia de pré-intervenção também é conhecida como morfologia original e respalda-se na concepção de Rodrigues (2005, p. 103), que relata que esta é uma "[...] morfologia cujos atributos como extensão, declividades, rupturas e mudanças de declives, dentre outros, não sofreram alterações significativas por intervenção antrópica direta ou indireta".

MÉTODO E TÉCNICAS A proposta deste trabalho se fundamenta na concepção de que o homem tem interferido de forma cada vez mais rápida e agressiva na dinâmica dos processos que ocorrem dentro do campo geomorfológico, o que leva a defender a ideia de que a humanidade vivencia uma nova 
realidade ambiental (Vicente \& Perez Filho 2003). Dessa maneira, o homem passa da condição de agente dinamizador do relevo para a de agente geomorfológico independente, que cria novas formas de relevo e interfere nos processos anteriormente estabelecidos, guiado, sobretudo, por necessidades intrínsecas ao sistema socioeconômico em vigência.

Essa concepção vai ao encontro dos ditames da antropogeomorfologia, que possui seus alicerces na perspectiva sistêmica. Assim, Christofoletti (1999b) cita que, relacionado ao estudo das organizações espaciais, deve-se abordar dois componentes básicos que permitam entender a estrutura e o funcionamento dessas, ou seja, as características dos sistemas ambientais físicos e as do sistema socioeconômico. Esse tipo de abordagem possibilita, de acordo com Rodrigues (2001), entender as influências antropogênicas sobre os fenômenos naturais, que resultam em um estado derivado do sistema original, configurando-se tais situações em foco de análise desta pesquisa.

A antropogeomorfolofia se utiliza da adequação de instrumentos clássicos da geomorfologia para a identificação das alterações causadas pelas ações antrópicas ao longo do espaço e do tempo (Rodrigues 2005). Dentro desta perspectiva, Rodrigues (2005, p. 101), recomenda que se deva partir “[...] do reconhecimento cartográfico das unidades morfológicas originais para posteriormente considerar a sequência de intervenções antrópicas nas formas e na distribuição de materiais superficiais", os quais podem ser denominados de quadro de perturbação ativa ou de pós-perturbação. Essa cartografia é denominada de "geocartografia geomorfológica retrospectiva" ou "evolutiva" e apoia-se no estudo sistemático morfológico, composto pelo tripé: materiais, forma e processos (Hart 1986, apud Rodrigues 2005).

Nir (1983) destaca que a análise antropogênica deve ocorrer de forma integrada, e contemplar aspectos como a abordagem histórica das intervenções humanas sobre as formas do relevo; a análise da dinâmica socioeconômica; e a investigação dos ambientes antropogênicos a partir de estimativas quantitativas de extensão, taxas ou grau dos processos observados. Assim, recorreu-se às técnicas da cartografia temática para gerar cartas de uso da terra e geomorfológicas evolutivas para posterior obtenção de dados quantitativos que comprovem a existência de alterações no meio físico de cunho antrópico.
Cartas de uso da terra A elaboração das cartas de uso da terra, aplicada a períodos distintos, possibilitou inferir a análise da evolução ao longo do tempo das modificações ocorridas na bacia hidrográfica do Ribeirão Santa Gertrudes, principalmente no que diz respeito às alterações provenientes das atividades agrícolas e mineradoras de argila.

Identificou-se o uso da terra dos cenários de 1962 e 2006 com base em fotografias aéreas nas escalas aproximadas de 1:25.000 e 1:30.000, respectivamente. A interpretação das fotografias aéreas ocorreu de acordo com o estudo de Ceron \& Diniz (1966), os quais utilizam a identificação dos elementos de interpretação, tais como: cor, textura, forma da parcela, dimensão da área cultivada, dimensão dos campos de cultivo, altura, espaçamento, restos de colheita e arranjo espacial.

As classes de uso da terra foram estabelecidas de acordo com a proposta de Anderson et al. (1979), que propõem uma estrutura de sistema de classificação do uso da terra baseada em produtos de sensoriamento remoto: imagens de satélite e fotografias aéreas. Esta proposta adapta-se às necessidades dessa pesquisa por se apresentar flexível e permitir, sobretudo para dados de sensoriamento remoto tomados de altitudes médias e baixas, a inserção de novas categorias de uso da terra em sua estrutura, além da exclusão de categorias pré-definidas, de acordo com as necessidades específicas do usuário (Anderson et al. 1979). Assim, foram identificadas 12 classes de uso da terra durante este estudo (Fig. 2).

As fotografias aéreas foram escaneadas em resolução de 300 dpi e georreferenciadas no programa ArcGis 9.3, de acordo com a carta topográfica executada pela Secretaria de Economia e Planejamento do estado de São Paulo, no ano de 1979, na escala 1:10.000, equidistância entre as curvas de nível de $5 \mathrm{~m}$, Datum horizontal Córrego Alegre (MG) e Datum vertical Marégrafo de Imbituba (SC), o que permitiu gerar o mosaico da área de estudo. Ao considerar a distorção de borda intrínseca às fotografias

\begin{tabular}{|c|c|}
\hline 田 $\begin{array}{l}\text { Complexos industriais } \\
\mathrm{e} \text { comerciais }\end{array}$ & $\begin{array}{l}\text { Cobertura herbácea em antigas } \\
\text { arreas de mineração }\end{array}$ \\
\hline Citrus & $\begin{array}{l}\text { Matas ciliares e } \\
\text { florestas de encostas }\end{array}$ \\
\hline Cana-de-açúcar & Lagos e reservatórios \\
\hline$\Delta \nabla$ Silvicultura & Terras úmidas \\
\hline SWW Pasto limpo & Minas a céu aberto \\
\hline Eg Pasto sujo & E:g Cultura anual \\
\hline
\end{tabular}

Figura 2 - Classes de uso da terra mapeadas na bacia hidrográfica do Ribeirão Santa Gertrudes. 
aéreas, a quantidade de pontos utilizados no georreferenciamento dessas variou de imagem para imagem, nas quais se procurou identificar o máximo de feições coexistentes entre elas e a carta topográfica. O procedimento operacional adotado nesta classificação dividiu-se em três etapas: identificar diretamente na tela do computador as classes de uso da terra passíveis de serem assinaladas sem erro; utilizar pares estereoscópicos de fotografias aéreas para sanar eventuais dúvidas; realizar trabalho de campo para averiguação das dúvidas atreladas à fotointerpretação.

Cartografia geomorfológica evolutiva As cartas geomorfológicas de detalhe fornecem subsídios para uma análise minuciosa de todos os elementos que compõem o relevo, sejam esses naturais ou derivados da ação antrópica, os quais são expressos em formas de símbolos e cores que se sobrepõem, conferindo-lhes grande complexidade, seja ao gerá-los ou interpretá-los (Cunha 2001, Paschoal et al. 2010).

As informações geradas pelo mapeamento geomorfológico do ano de 1962 referem-se a um quadro com pouca intervenção em relação às atividades de mineração, no qual é possível identificar a geomorfologia mais próxima à original da área. Porém, esse cenário já apresenta alterações em sua geomorfologia devido ao uso da terra, vinculados às atividades agrícolas. A fase de perturbação ativa, representada pelo ano de 2006, retrata um cenário onde há modificações expressivas e que implicam em alteração nas dimensões de elementos passíveis de serem mensurados, permitindo configurá-lo como representativo da geomorfologia antropogênica.

A elaboração do mapeamento geomorfológico da área de estudo seguiu a proposta de Tricart (1965), a qual afirma que esse tipo de mapeamento deve comportar quatro tipos de informações de naturezas diferentes, a saber: morfometria, morfografia, morfogênese e cronologia. Os dados morfométricos representam valores quantitativos e foram compilados da base cartográfica e representados por meio das curvas de nível e cotas altimétricas. As informações morfográficas foram obtidas a partir da interpretação de pares estereoscópicos de fotografias aéreas dos anos de 1962 e 2006, possuindo a finalidade de representar diferentes feições topográficas. Os elementos relacionados à morfogênese encontram-se associados aos símbolos utilizados na morfografia, que além das formas indicam o agente responsável por sua origem. Informações referentes à cronologia são parciais, sendo representadas por meio dos dados que compõem a carta geológica e se remetem ao período em que se formaram as rochas que dão sustentação ao relevo. As informações referentes à cronologia e dados litológicos foram indicadas em separado (Fig. 1), diante da necessidade de proporcionar maior legibilidade às simbologias utilizadas nas cartas geomorfológicas.

As simbologias que compõem a legenda (Fig. 3) se pautaram principalmente na adaptação das propostas de Tricart (1965) e Verstappen \& Zuidan (1975). Com relação à utilização de símbolos para a representação das feições antrópicas na área, recorreu-se a outras fontes como Simon (2007) e Paschoal et al. (2010). A seleção de simbologias utilizadas por diferentes pesquisadores encontra respaldo nas considerações de Cunha (2001) sobre o mapeamento geomorfológico, e possui o propósito de facilitar a legibilidade das feições geomorfológicas mapeadas e contribuir com a análise ambiental.

\section{RESULTADO E DISCUSSÕES Como re-} sultados da aplicação das técnicas supracitadas, obtiveram-se as cartas de uso da terra (Figs. 4 e 5) e geomorfológicas (Figs. 6 e 7), ambos nos anos de 1962 e 2006, respectivamente. As informações obtidas permitem inferir considerações relevantes a respeito da dinâmica do uso da terra e sua interferência no modelado hidrogeomorfológico, assim como na (re)mobilização de materiais de superfície e subsuperfície, evolução dos processos denudativos, áreas de acúmulo de sedimentos, entre outros, que se destacam na área da bacia hidrográfica do Ribeirão Santa Gertrudes.

Uso da terra Após e elaboração das cartas de uso ilustradas nas Figs. 4 e 5, pôde-se extrair os dados que compõem a Fig. 8.

O principal uso da terra no cenário de 1962 é representado pela cultura da cana-de-açúcar, distribuída por $34,2 \%$ da área total da bacia hidrográfica do Ribeirão Santa Gertrudes, a qual continuou a expandir e passou a ocupar $60,7 \%$ da área total no ano de 2006 (Fig. 8). O cultivo canavieiro tornou-se mais expressivo nas últimas décadas diante dos estímulos do Governo Federal por meio da campanha Pró-álcool, instituída pelo Decreto n ${ }^{\circ} 76593$ em 14 de novembro de 1975, após a crise do petróleo em 1973, o qual visava a substituição, em grande escala, do uso de combustíveis derivados do petróleo pelo álcool. 


\begin{tabular}{|c|c|c|c|c|}
\hline Dados Estruturais & \multicolumn{3}{|l|}{ Falha inferida } & ムーー \\
\hline & \multirow{3}{*}{ Vertente } & \multicolumn{2}{|l|}{ Côncava } & $\Psi$ \\
\hline & & \multicolumn{2}{|l|}{ Convexa } & ש \\
\hline & & \multicolumn{2}{|l|}{ Retilínea } & 1 \\
\hline & \multirow{2}{*}{ Linha de cumeada } & \multicolumn{2}{|l|}{ Suave } & $-\cdots-1$ \\
\hline & & \multicolumn{2}{|l|}{ Íngreme } & $-x-x-x-$ \\
\hline $\begin{array}{l}\text { Formas de } \\
\text { Vertentes e Interflúvios }\end{array}$ & & \multicolumn{2}{|l|}{ Colo topográfico } & 5 \\
\hline vertentes e intermuvios & & \multicolumn{2}{|l|}{ Sulco } & mus \\
\hline & $\begin{array}{l}\text { Formas } \\
\text { localizadas }\end{array}$ & \multicolumn{2}{|l|}{ Ravina } & $\Delta$ \\
\hline & & \multicolumn{2}{|l|}{ Voçoroca } & ه \\
\hline & Feições & \multicolumn{2}{|l|}{ Caimento topográfico } & - \\
\hline & topográficas e & \multirow{2}{*}{\multicolumn{2}{|c|}{$\begin{array}{l}\text { Curva de nível } \\
\text { Ponto cotado }\end{array}$}} & 545 \\
\hline & morfométricas & & & $\times 700$ \\
\hline \multirow{8}{*}{$\begin{array}{l}\text { Ação das Águas } \\
\text { Correntes }\end{array}$} & \multirow{3}{*}{$\begin{array}{l}\text { Feições } \\
\text { hidrográficas }\end{array}$} & \multicolumn{2}{|l|}{ Canal Fluvial } & $<$ \\
\hline & & \multicolumn{2}{|c|}{ Canal Pluvial } & $-x=$ \\
\hline & & \multicolumn{2}{|c|}{ Área de alagamento sazonal } & E望 \\
\hline & $\begin{array}{l}\text { Formas de } \\
\text { acumulação }\end{array}$ & \multicolumn{2}{|c|}{ Área de acumulação fluvial } & $\because \because \%$ \\
\hline & \multirow{4}{*}{$\begin{array}{l}\text { Modelado de } \\
\text { entalhe }\end{array}$} & \multirow{2}{*}{ Ruptura topográfica } & Suave & Th \\
\hline & & & Íngreme & ח \\
\hline & & \multirow{2}{*}{ Fundo de vale } & Em V & $\rightarrow \longrightarrow$ \\
\hline & & & Fundo plano & 了? \\
\hline \multirow{12}{*}{$\begin{array}{l}\text { Modelado } \\
\text { Antrópico }\end{array}$} & \multirow{2}{*}{\multicolumn{2}{|c|}{ Mineração }} & Ativa & $x$ \\
\hline & & & Desativa & $x$ \\
\hline & \multirow{2}{*}{\multicolumn{2}{|c|}{$\begin{array}{l}\text { Colina residual derivada de atividade } \\
\text { minerária }\end{array}$}} & Suave & 离 \\
\hline & & & Abrupta & 妾紧 \\
\hline & \multirow{2}{*}{\multicolumn{2}{|c|}{ Patamares em cava de mineração }} & Suave & Th \\
\hline & & & Abrupto & $\pi$ m \\
\hline & \multicolumn{3}{|c|}{ Terraço agrícola / Curvas de nível } & $\pi \pi$ \\
\hline & \multicolumn{3}{|c|}{ Aterro para vias de circulação } & ॠ \\
\hline & Corte para vias de & ação & & 도 \\
\hline & Conduto & & & $\mathbf{I}$ \\
\hline & Cavas de mineração a & do nível do lençol freático & & a \\
\hline & Canal Fluvial sob i & rência antrópica & & \#\#+ \\
\hline
\end{tabular}

Figura 3 - Legenda que compõe a carta geomorfológica da bacia hidrográfica do Ribeirão Santa Gertrudes.

O Pró-álcool começa a deixar de ser um programa do Governo Federal em 1990, quando os mecanismos de suporte e subsídios concedidos ao setor passaram a ser retirados progressivamente, até que, no ano de 2002, esse setor atinge plena liberdade na fixação dos preços e consagra-se como um programa energético consolidado. Porém, o mesmo continua a contar com uma política tributária favorável, se comparado à gasolina (Nogueira 2007) e, dessa maneira, a cultura canavieira tornou-se cada vez mais expressiva.

Além do cultivo da cana-de-açúcar, outras parcelas do uso da terra também apresentaram um incremento nos dois cenários analisados, como é o caso das matas ciliares e florestas de encostas, que deixaram o patamar de 1,4\% no cenário de 1962, atingindo $3,1 \%$ da área total da bacia hidrográfica do Ribeirão Santa Gertrudes em 2006 (Fig. 8), e os diversos tipos de usos vinculados à atividade minerária.

Os usos da terra que se encontram atrelados à atividade minerária referem-se à cobertura herbácea em antigas áreas de mineração, reservatórios artificiais e minas a céu aberto. As parcelas de uso da terra destinadas à cobertura herbácea em antigas áreas de mineração deixaram o patamar de 1,7\% em 1962 e passaram a característica comum de $11 \%$ da área de estudo no ano de 2006, e os reservatórios artificiais que em 1962 ocupavam 0,3\% da área, no ano de 2006 atingiram $1,5 \%$ do uso da terra (Fig. 8). Esses aumentos estão relacionados às antigas cavas de mineração para explotação de argila que foram desativadas, favorecendo o crescimento da cobertura herbácea e o retorno ao nível normal do lençol freático nessas áreas, as quais atingiram grandes profundidades, fato que possibilitou a criação dos reservatórios artificiais.

As áreas de uso da terra relacionada às minas a céu aberto na bacia hidrográfica do Ribeirão Santa Gertrudes também apresentaram um aumento, ou seja, passou de 1,2\% no ano de 1962 para $6,5 \%$ no ano de 2006 (Fig. 8). Esse aumento foi influenciado pelas transformações e modernizações 


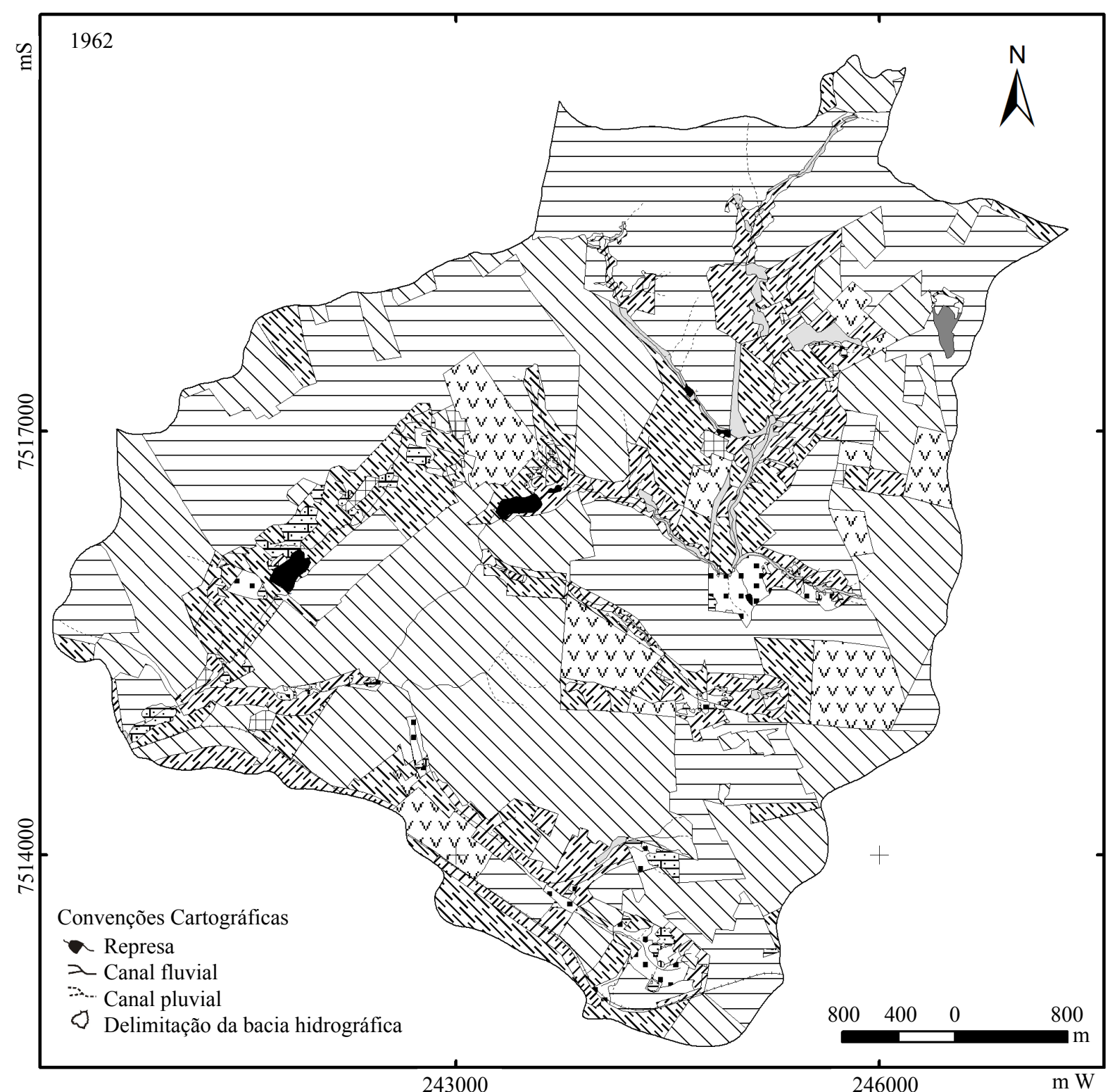

Figura 4 - Cartas de uso da terra na bacia hidrográfica do Ribeirão Santa Gertrudes no ano de 1962. A legenda referente às classes de uso da terra encontra-se na Fig. 2.

do setor cerâmico, sobretudo a partir da década de 1990, onde os métodos artesanais foram substituídos por modernos sistemas industriais de monoqueima, o que permitiu fazer com que as cerâmicas da região pudessem passar a competir com as demais existentes, não apenas em território nacional, como também no mercado externo. Esse salto produtivo atraiu novas indústrias do setor para a região, em especial indústrias de pisos e revestimentos, o que impulsionou uma desenfreada competitividade entre essas empresas no que diz respeito à aquisição dos direitos à extração mineral da argila.

O uso da terra classificado como área de alagamento sazonal na bacia hidrográfica do Ribeirão Santa Gertrudes também sofreu um pequeno acréscimo, pois passou de $0,1 \%$ em 1962, para 0,2\% em 2006 (Fig. 8). Essa área de alagamento sazonal vincula-se às inundações periódicas de acordo com as estações mais chuvosas do ano. A parcela de uso da terra referente às culturas anuais na bacia hidrográfica do Ribeirão Santa Gertrudes somente foi passível de registro no cenário de 2006, responsável por ocupar 4,2\% da área total (Fig. 8), no qual se destacam a produção do feijão e do milho, principalmente em regiões próximas ou em antigas áreas de mineração.

Face ao crescimento das classes de uso da terra supracitadas na bacia hidrográfica do Ribeirão Santa Gertrudes, outras cinco registraram um declínio ao longo do tempo: citricultura, silvicultura, 


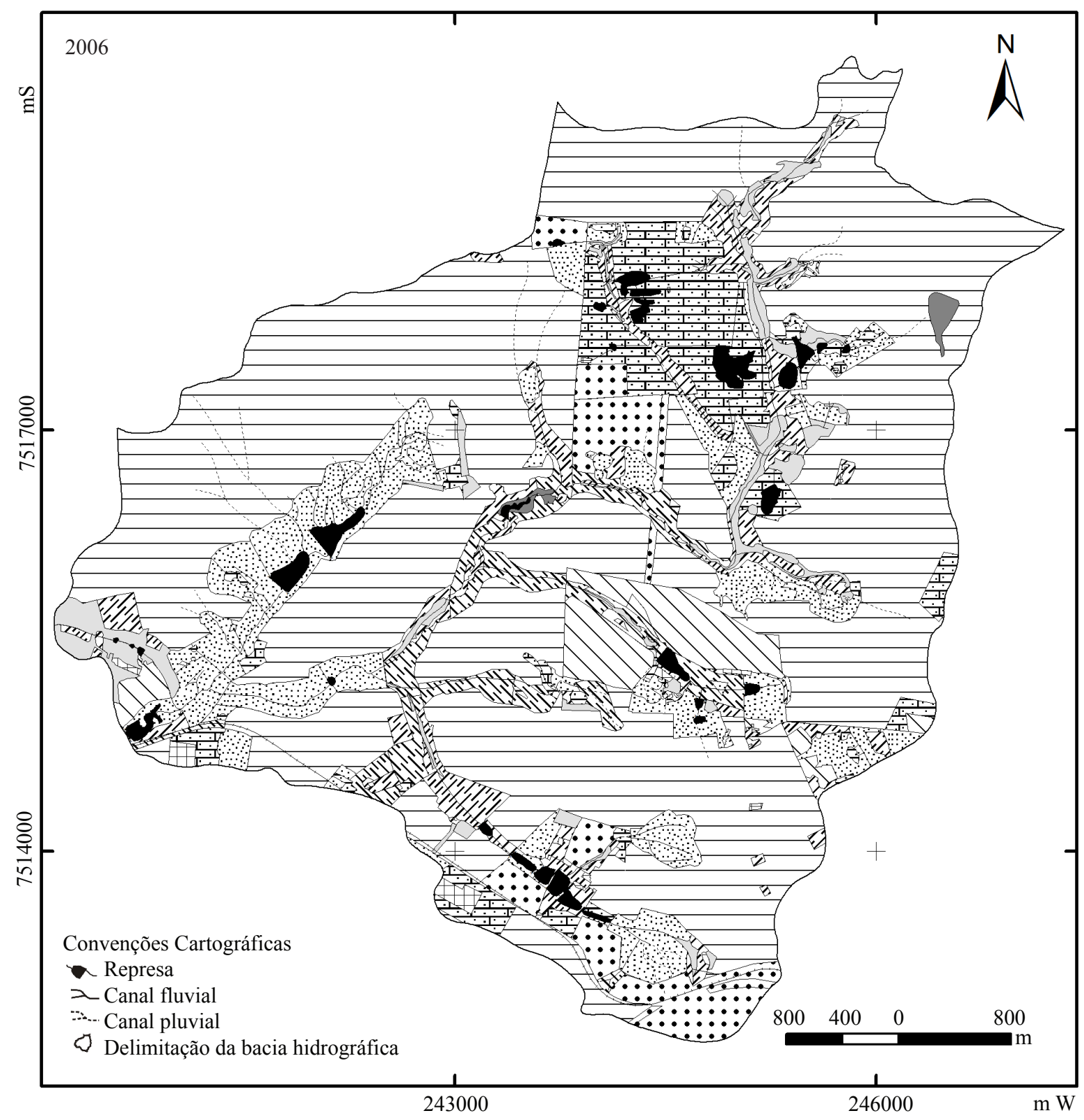

Figura 5 - Cartas de uso da terra na bacia hidrográfica do Ribeirão Santa Gertrudes no ano de 2006. A legenda referente às classes de uso da terra encontra-se na Fig. 2.

pasto limpo, pasto sujo e residências rurais e áreas industriais (Fig. 8). A citricultura, que no ano de 1962 ocupava $5,9 \%$ da área total desta bacia, deixou de ser cultivada. A silvicultura ocupava $33,4 \%$ da área em 1962 e foi reduzida para 3,4\% em 2006. No geral, as áreas destinadas à silvicultura foram substituídas pela cultura da cana-de-açúcar. A somatória dos valores de área ocupada por pastos limpos e pastos sujos mostra-se significativa no cenário de 1962, na ordem de $21,4 \%$, sendo o pasto sujo responsável por $9,1 \%$ e o pasto limpo por $12,3 \%$. Em 2006, essa somatória tornou-se pouco expressiva, totalizando $9 \%$ do uso da terra na área de estudo, dos quais 3,6\% eram destinados aos campos limpos e 5,4\% aos pastos sujos.
A classe de uso e ocupação da terra destinada às residências rurais e áreas industriais na bacia hidrográfica do Ribeirão Santa Gertrudes deixou de ocupar $0,5 \%$ e passou para $0,4 \%$ nos anos de 1962 e 2006, respectivamente. Essa diminuição de áreas construídas relaciona-se no geral às estruturas montadas ao lado de minerações durante seu período de funcionamento e que são removidas após sua desativação. Esse fato justifica-se diante da paralisação da explotação das lavras, desde outubro do ano de 2005, pelas indústrias que ali operavam. A paralisação ocorreu devido a problemas com o licenciamento ambiental, que está em fase de regularização via EIA-RIMA, pois as parcelas mineradas não continham os planos de recuperação 


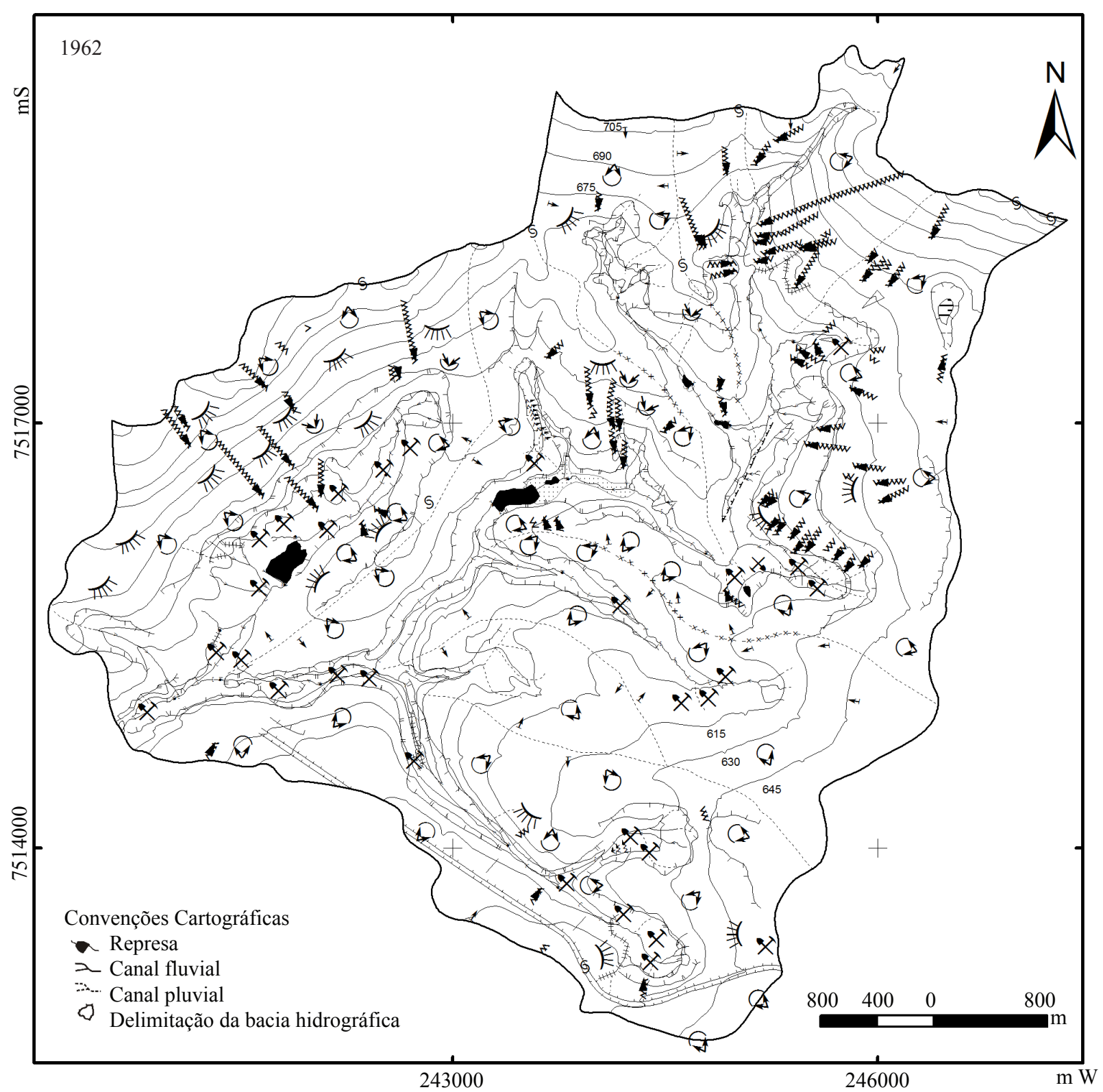

Figura 6 - Cartas geomorfológicas da bacia hidrográfica do Ribeirão Santa Gertrudes no ano de 1962. A legenda referente às cartas geomorfológicas encontra-se na Fig. 3.

das áreas degradadas, conforme previsto inicialmente na Política Nacional do Meio Ambiente (Inciso VIII do Artigo $\mathrm{n}^{\mathrm{0}} 2$, da Lei Federal 6.938 de 31 de agosto de 1981), nos Parágrafos $2^{\circ}$ e $3^{\circ}$ do Artigo $n^{\circ} 225$, da Constituição Federal de 1988 e no Decreto Federal n ${ }^{\circ}$ 97632, de 10 de abril de 1989.

\section{Geomorfologia}

A Fig. 9 ilustra a evolução de elementos geomorfológicos representativos de processos erosivos e deposicionais em cenário de pré-intervenção (1962) e perturbação ativa (2006) na bacia hidrográfica do Ribeirão Santa Gertrudes.

$\mathrm{O}$ crescimento de atividades vinculadas à explotação da argila e as destinadas à agricultura, sobretudo à cultura da cana-de-açúcar, alterou consideravelmente as características geomorfológicas entre os cenários de 1962 e 2006 na bacia hidrográfica do Ribeirão Santa Gertrudes, desencadeando desequilíbrios nos sistemas ambientais físicos da área, como é o caso da dinamização dos processos erosivos, de transporte e deposição de sedimentos dentro do sistema em questão. Esses desequilíbrios podem ser constatados diante da análise comparativa entre as cartas geomorfológicas dos anos de 1962 e 2006, que retratam as alterações ocasionadas pelos diversos usos da terra nessa bacia.

As rupturas topográficas marcam a evolução da vertente, ou seja, evidenciam que ao longo desta 


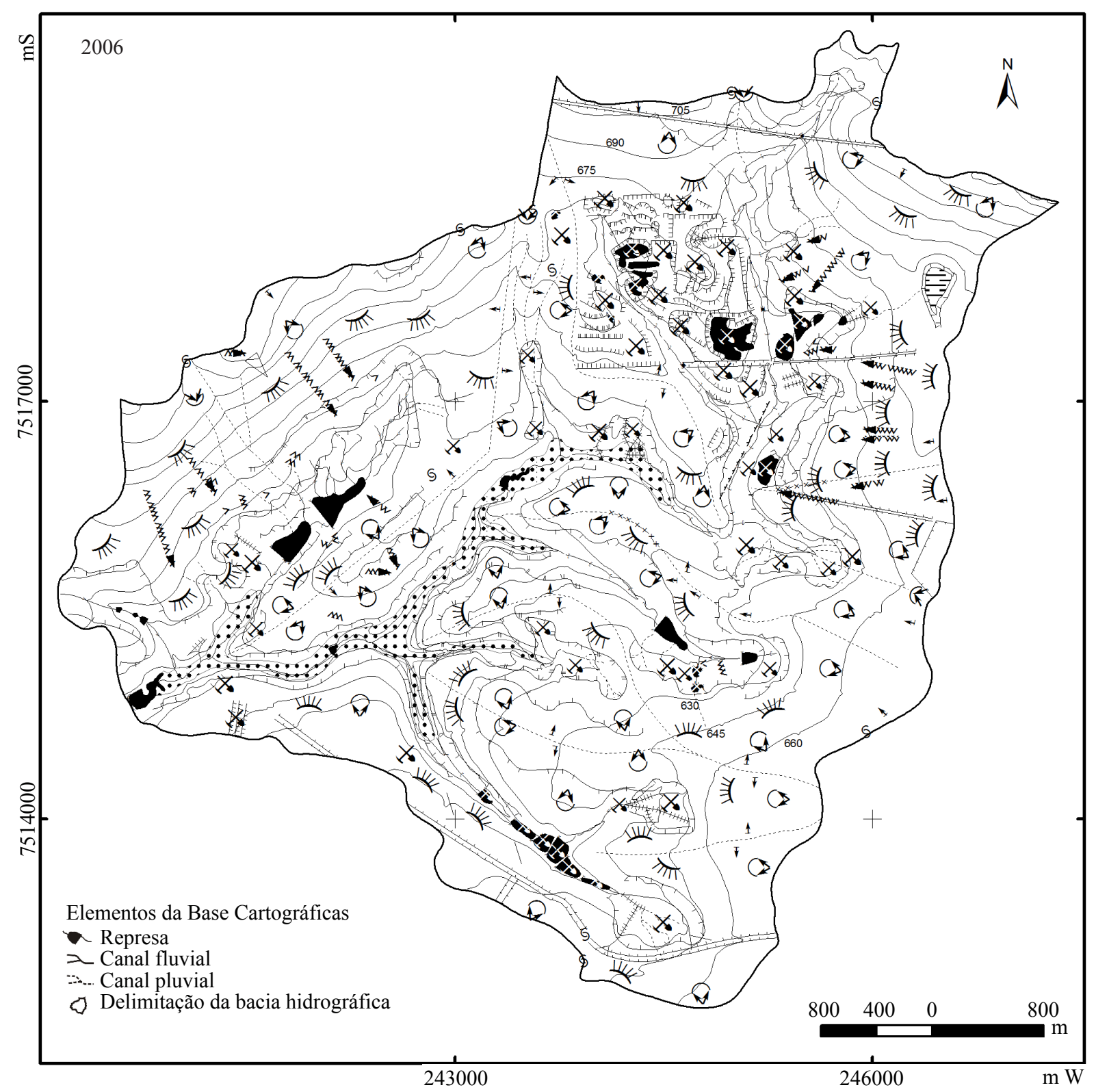

Figura 7 - Cartas geomorfológicas da bacia hidrográfica do Ribeirão Santa Gertrudes no ano de 2006. A legenda referente às cartas geomorfológicas encontra-se na Fig. 3.

há um processo erosivo diferenciado. Essas rupturas são feições que podem ter sua origem em fatores naturais, tais como em regiões onde há contato entre diferentes materiais que compõem a litologia. Porém, fatores antrópicos, atrelados ao tipo de uso da terra, também são responsáveis pela dinamização deste processo, fazendo surgir novas rupturas ou descaracterizando outras mais antigas. Assim, foi possível constatar que a somatória das extensões lineares das rupturas topográficas abruptas e suaves manteve-se praticamente constante entre os anos de 1962 $(57,3 \mathrm{~km})$ e $2006(56,1 \mathrm{~km})$.

No cenário de 1962, a maior parte das rupturas topográficas na bacia hidrográfica do Ribeirão Santa
Gertrudes era considerada abrupta, com um total de 34,8 $\mathrm{km}$, possuindo as rupturas topográficas suaves uma extensão de 22,5 km (Fig. 9A). No cenário de 2006, essa situação se inverte, sendo que $44,8 \mathrm{~km}$ de extensão são relacionados às rupturas topográficas suaves e apenas 12,1 km as rupturas topográficas abruptas (Fig. 9A). Em 1962, as rupturas topográficas abruptas ocorriam com grande frequência entre os locais de contato da silvicultura e/ou cana-de-açúcar com os pastos sujos ou limpos. No ano de 2006, as rupturas topográficas nessa bacia apresentam-se mais suavizadas, fato atrelado à expansão e emprego de técnicas agrícolas mais modernas nas áreas de cultivos de cana-de-açúcar, tais como: plantações em curva de nível e terraceamentos. Este fato 


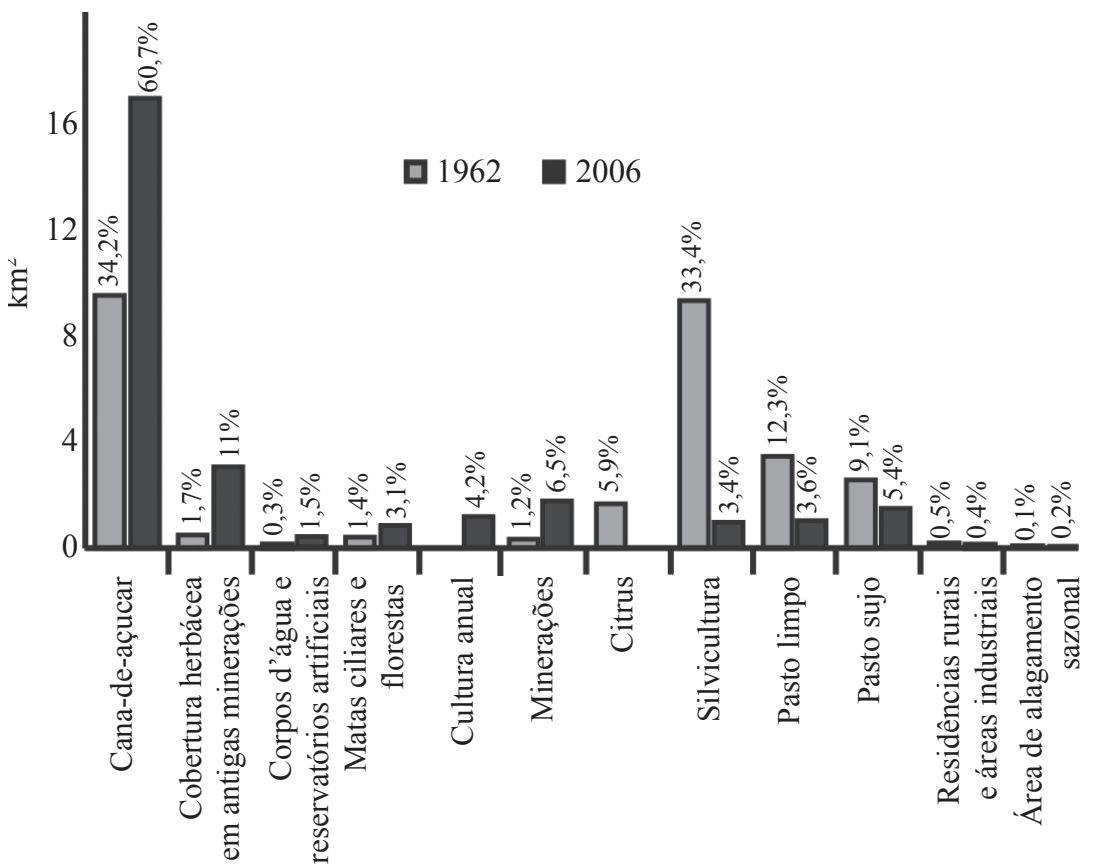

Figura 8 - Evolução do uso da terra em cenário de pré-intervenção (1962) e perturbação ativa (2006) na bacia hidrográfica do Ribeirão Santa Gertrudes.

evidencia que a morfologia das vertentes tem se alterado de acordo com o tipo de uso da terra e de técnicas de manejo aplicadas às mesmas.

A terceira forma indicativa de processos erosivos a ser considerada na bacia do Ribeirão Santa Gertrudes constitui-se na extensão dos sulcos erosivos. Os cenários de 1962 e 2006 apresentam amplo recuo na extensão das áreas ocupadas por essa feição, passando de 15,6 para $6,1 \mathrm{~km}$, respectivamente (Fig. 9A). Essa diminuição na extensão dos sulcos também se relaciona ao aumento de parcelas de uso da terra atrelada ao cultivo da cana-de-açúcar, que diante do uso intenso de maquinários agrícolas em diferentes fases de sua produção, como no preparo do solo e estabelecimento das curvas de nível e terraceamento, ou até mesmo na fase de colheita, quando caminhões transitam pelo terreno, reorganizando as camadas superficiais do solo, provocam a destruição de grande parte dessas feições. Contudo, esses fatos não inibem totalmente sua atuação, conforme é possível observar por meio da análise do cenário exposto na Fig. 7, assim como ao observado para as rupturas topográficas abruptas nessa bacia.

Os patamares em cavas de mineração, tanto suaves $(12,1 \mathrm{~km})$ quanto abruptos $(5,9 \mathrm{~km})$, são apenas identificados no cenário de 2006 (Fig. 9A), fruto da ação antrópica que explotou grandes quantidades de matéria-prima e que descaracterizou um extenso interflúvio existente no setor norte da bacia
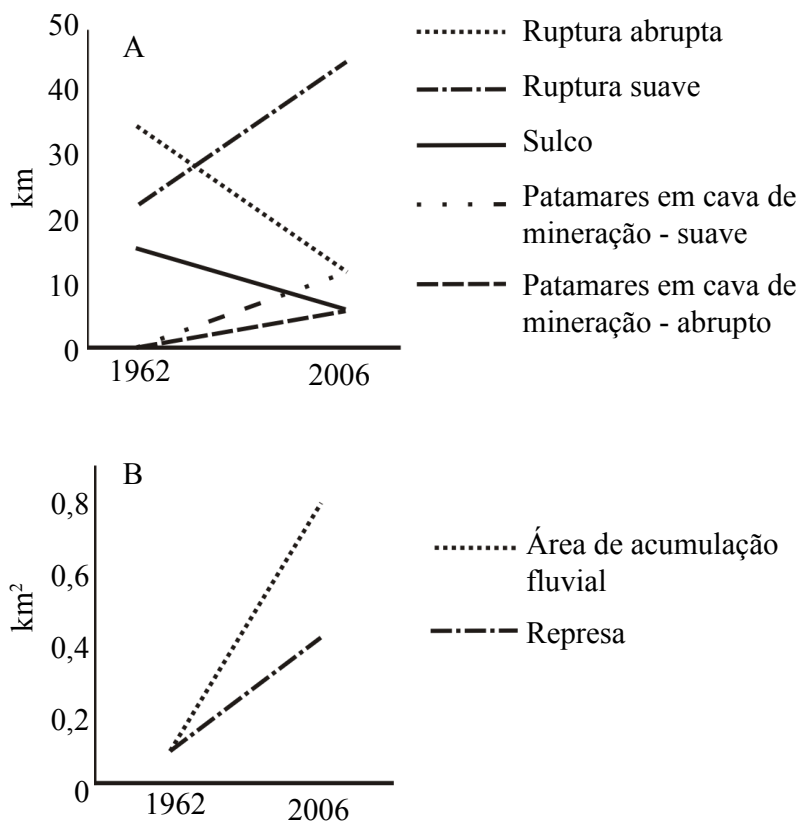

Figura 9 - Evolução de elementos geomorfológicos representativos de processos erosivos (A) $e$ deposicionais (B) em cenário de pré-intervenção (1962) e perturbação ativa (2006) na bacia hidrográfica do Ribeirão Santa Gertrudes.

hidrográfica do Ribeirão Santa Gertrudes. Neste caso, é importante salientar a predominância dos símbolos geomorfológicos sobre os valores das curvas de nível e pontos cotados, para uma leitura correta da carta em questão. Esse fato comprova que as alterações já atingiram o nível de desenvolvimento de uma 
geomorfologia antropogênica na área. Os patamares gerados nas cava de mineração e que possuem ruptura suave foram realizados de acordo com a orientação das curvas de nível. Enquanto os patamares em cava de mineração classificados como abruptos ocorrem no entorno das grandes cavas de mineração.

Em relação aos processos de deposição de sedimentos dentro da bacia hidrográfica do Ribeirão Santa Gertrudes, pode-se constatar que houve um aumento de área no cenário de 2006 vinculados às áreas de acumulação fluvial e de represas originadas em antigas cavas de mineração (Fig. 9B). A área ocupada pelas represas artificiais nessa bacia era de $0,1 \mathrm{~km}^{2}$ no ano de 1962 ,

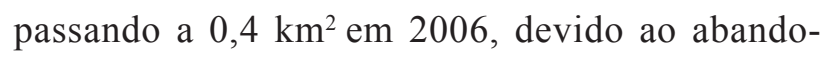
no de antigas cavas de mineração, fato explicado anteriormente.

A área de acumulação fluvial também aumentou. No ano de 1962, o acúmulo de sedimentos nos fundos de vale era da ordem de $0,1 \mathrm{~km}^{2}$, e possivelmente relaciona-se a um fenômeno natural que ocorre em áreas restritas e em escala de tempo geológico, vinculando-se à busca pelo perfil de equilíbrio da drenagem. No ano de 2006, a área de acumulação fluvial passou para o valor de $0,8 \mathrm{~km}^{2}$. O aumento da área de acumulação de sedimentos na bacia hidrográfica do Ribeirão Santa Gertrudes caracterizou-se devido às grandes quantidades de sedimentos depositados nos fundos de vale, principalmente no baixo e médio curso do Ribeirão Santa Gertrudes, proveniente da explotação das minas de argila e da erosão laminar devido ao uso da terra. Este fato evidencia uma brusca interferência de ações realizadas pelo homem no sistema em questão e que tem dado origem a novas formas no relevo e realocado grande quantidade de matéria, passíveis de serem mapeadas em escala de tempo histórica.

CONCLUSÕES O método da teoria geral dos sistemas com ênfase em geomorfologia antropogênica, em conjunto com diversas técnicas da cartografia temática e geomorfológica, permitiram averiguar de maneira integrada e eficiente os elementos envolvidos nas transformações ocorridas na área de estudo. Ressalva é feita ao fato dessa metodologia propiciar uma discussão mais aprofundada dos aspectos dos sistemas ambientais físicos face aos aspectos do sistema socioeconômico. Dessa maneira, as discussões sobre o uso da terra e sua dinâmica pautam-se, principalmente, na análise das características observáveis da paisagem, a partir do qual foi inferida a dinâmica do sistema socioeconômico.

A escolha da bacia hidrográfica como unidade de estudo, com a finalidade de realizar avaliações físicas de ambientes altamente impactados por minerações de argila e atividades agrícolas, mostrou-se satisfatória. Desequilíbrios nas taxas de processos denudacionais, de sedimentação e da dinâmica de circulação d'água superficial e de subsuperfície puderam ser detectadas por meio da análise dos mapeamentos, podendo assim ser avaliada de forma sistêmica através do estudo da bacia hidrográfica, já que os processos geradores das formas encontradas repercutem em escalas mais amplas, trazendo consequências que vão além de sua ocorrência pontual no relevo.

Os resultados indicam que a cultura da cana-de-açúcar, a silvicultura e as pastagens eram as principais parcelas de uso da terra, no ano de 1962, nessa bacia. Contudo, a instalação do Pólo Cerâmico de Santa Gertrudes e o incentivo governamental ao cultivo de cana-de-açúcar fizeram com que as áreas destinadas às atividades minerárias e canavieiras passassem a ocupar 79,7\% da área da bacia, face aos $37,4 \%$ que ocupavam em 1962 , configurando-as como principais mecanismos de controle de cunho antrópico sobre os sistemas ambientais físicos na área estudada.

Dessa forma, os dados obtidos através dos cenários de 2006, mostram que devido à atividade de mineração, a paisagem apresentou transformações, na qual se destaca a descaracterização de um amplo interflúvio, que foi remodelado por meio da criação de patamares em áreas de cavas de mineração a céu aberto, bem como a explotação abaixo do nível do lençol freático, que originou vários reservatórios artificiais na área. Além disso, a atividade agrícola também alterou toda a dinâmica de escoamento superficial e fez diminuir o surgimento de processos erosivos lineares, através do estabelecimento de técnicas agrícolas modernas, e remobilizou sedimentos para as áreas de fundo de vale, aumentando com isso as áreas de acumulação fluvial.

Como consequência das análises da dinâmica do uso da terra e suas implicações sobre a geomorfologia, torna-se possível apontar algumas medidas de redução aos impactos ambientais, tais 
como a adoção de rotatividade de culturas, manutenção das medidas de manejo, como a implantação de curvas de nível e terraceamento e a recuperação das áreas de proteção permanente (APP).

Vinculado às áreas de mineração de argila, é possível citar a necessidade de implantação de canais e sistemas de drenagem, enriquecimento da cobertura vegetal, construção de barreiras com elementos filtrantes para sedimentos, implantação de programas de gestão de resíduos e de treinamento ambiental dos trabalhadores e de melhoria das vias de tráfego, implantação de obras específicas de estabilização de taludes, programas de monitoramento da qualidade das águas superficiais e subterrâneas e de monitoramento hidrológico.

Assim, este trabalho, que associa estudos do uso da terra à cartografia geomorfológica evolutiva, possibilitou o fornecimento de parâmetros para um diagnóstico geral da bacia hidrográfica do Ribeirão Santa Gertrudes, os quais devem ser utilizados durante a elaboração de programas referentes ao planejamento e gestão ambiental.

AGRADECIMENTOS Os autores agradecem à Fundação de Amparo à Pesquisa do Estado de São Paulo (FAPESP) pelo suporte financeiro de trabalho (processo $\mathrm{n}^{\circ} 2005 / 59203-1$ e $\mathrm{n}^{\circ}$ 2009/01761-0), bem como ao Prof. Dr. Norberto Morales e a Profa. Dra. Maria Isabel C. de Freitas pelas sugestões feitas ao longo do desenvolvimento desta pesquisa. Os autores também gostariam de agradecer a um revisor anônimo pelas sugestões recomendadas, as quais contribuíram para a melhora deste manuscrito.

\section{Referências}

Anderson J.R., Hardy E.E., Roach J.T., Witmer R.E. 1979. Sistema de classificação do uso da terra e do revestimento do solo para utilização com dados $e$ sensores remotos. Rio de Janeiro: IBGE, 78 p.

ASPACER (Associação Paulista das Cerâmicas de Revestimento). 2009. Estatísticas, 2009. Disponível em: http://www.aspacer.com.br/estatisticas/ est_2009_1.html. Acessado em: 18/06/2010.

El Banna M.M., Frihy O.E. 2009. Human-induced changes in the geomorphology of the northeastern coast of the Nile delta, Egypt. Geomorphology, 10(2009):772-778.

BNDES (Banco Nacional de Desenvolvimento Econômico e Social). 2006. Panorama do setor de revestimentos cerâmicos - Área industrial. Departamento de bens de consumo. Disponível em: http://www.bndes.gov.br/ conhecimento/relato/rs_rev_ceramicos.pdf. Acessado em: 01/05/2009.

Brasil. Ministério do Meio Ambiente. Conselho Nacional do Meio Ambiente. 2008. Resoluções do Conama: resoluções vigentes publicadas entre julho de 1984 e novembro de 2008. 2.ed, Brasília, CONAMA, 928 p.

Brousse G., Fassetta G.A., Cordier S. 2011 Evolution hydrogéomorphologique de la bande active de l’Ubaye (Alpes françaises du Sud) de 1956 à 2004 : contribution à la gestion des crues. Géomorphologie: relief, processus, environnement, 3(2011):307-318.

Ceron A.O. \& Diniz J.A.F. 1966. O uso das fotografias aéreas na identificação das formas de utilização agrícola da terra. Revista Brasileira de Geografia, 2(1966):161-173.

Christofoletti S.R. 1999a. Estudo mineralógico, químico e textural das rochas sedimentares da Formação Corumbatai "Jazida Cruzeiro”, e suas implicações nos processos e produtos cerâmicos. Dissertação de Mestrado em Geologia Regional, Instituto de Geociências e Ciências Exatas, Universidade Estadual Paulista, Rio Claro, 120 p.

Christofoletti A. 1999b. Modelagem de sistemas ambientais. São Paulo, Edgard Blücher, 236 p.

Corrêa. A.C.B. 2011. Antropogênese e Morfogênese sob a ação de eventos climáticos de alta magnitude no semiárido pernambucano: o caso da bacia do riacho Salgado. Revista Brasileira de Geomorfologia, 12(3):25-36.

Cunha C.M.L. 2001. A cartografia do relevo no contexto da gestão ambiental. Tese de Doutorado em Geociências, Instituto de Geociências e Ciências Exatas, Universidade Estadual Paulista, Rio Claro, 128 p.

Drew D. 1989. Processos Interativos Homem-Meio Ambiente. Trad. Santos J.A. Rio de Janeiro, Bertrand, 2. ed., 206 p.

EIA (Estudo de Impacto Ambiental). 2008. Complexo Argileiro de Santa Gertrudes. ASPACER (Associação Paulista das cerâmicas de revestimento).

Fujimoto N.S.V.M. 2005. Considerações sobre o ambiente urbano: um estudo com ênfase na geomorfologia urbana. Revista do Departamento de Geografia, São Paulo: FFLCH/USP, 16(2005):76-80.

Gaspar Junior L.A. 2003. Adição experimental de novos materiais às argilas da região do pólo cerâmico de Santa Gertrudes (SP). Tese de Doutorado em Geociências, Instituto de Geociências e Ciências Exatas, Universidade Estadual Paulista, Rio Claro, 170 p.

Gill T.E. 1996. Eolian sediments generated by anthropogenic disturbance of playas: human impacts on the geomorphic system and geomorphic 
impacts on the human system. Geomorphology, 17(1996):207-228.

Goudie A. 1986. The human impact on the natural environment. Cambridge, The MIT Press, 338 p. Disponível em: http://www.duke.edu/ haff/geomorph abs/neogeomorph\%20paper/neogeomorphology.pdf. Acessado em: 03/06/2010.

Goudie A. 1993. Human influence in geomorphology. Geomorphology, 7(1993):37-59.

Hooke J.M. 2006. Human impacts on fluvial systems in the Mediterranean region Geomorphology, 79(2006):311-335.

Haff P.K. 2001. Neogeomorphology, prediction, and the anthropic landscape. Durham, Division of Earth and Ocean Sciences, Nicholas School of the Environment and Earth Sciences, Duke University, p. 1-22.

Hart M.G. 1986. Geomorphology, pure and applied. London, George Allen e Unwin, 228 p.

Jean-Pierre L. 2004. Morphodynamique fluviale actuelle d'origine anthropique: exemples dans le bassin de la Loire (France). Géomorphologie: relief, processus, environnement, 2(2004):127-138.

Lentz E.E. \& Hapke. C.J. 2011.Geologic framework influences on the geomorphology of an anthropogenically modified barrier island: Assessment of dune/beach changes at Fire Island, New York. Geomorphology, 126(2011):82-96.

Levighin S.C. 2005. Problemas ambientais e impactos sociais provocados pela atividade ceramista nos municípios de Santa Gertrudes e Cordeirópolis (SP). Tese de Doutorado em Geografia, Instituto de Geociências e Ciências Exatas, Universidade Estadual Paulista, Rio Claro, $150 \mathrm{p}$.

Lóczy D. \& Gyenizse P. 2010. Human impact on topography in an urbanised mining area: Pécs, Southwest Hungary. Géomorphologie: relief, processus, environnement, 3(2010):287-300.

Nir D. 1983. Man, a geomorphological agent. Jerusalém, Keter Publishing House, 165 p.

Nogueira L.A.H. 2007. Biocombustiveis na América Latina: situação atual e perspectivas. São Paulo, Fundação Memorial da América Latina, 77 p.

Paschoal L.G., Conceição F.T., Cunha C.M.L. 2010. Utilização do ArcGis 9.3 na elaboração de simbologias para mapeamentos geomorfológicos: Uma aplicação na área do Complexo Argileiro de Santa Gertrudes/SP. In: VIII Simpósio Nacional de Geomorfologia, Recife, p. 1-13.

Pellogia A.U.G. 2005. A cidades, as vertentes e as várzeas: a transformação do relevo pela ação do homem no município de São Paulo. Revista do Departamento de Geografia, 16(2005):24-31.
Perez FilhoA. \& Quaresma C.C. 2011. Ação antrópica sobre as escalas temporais dos fenômenos geomorfológicos. Revista Brasileira de Geomorfologia, 12(3):83-90.

Reis L.V.S. 2009. Mananciais de abastecimento público: Algumas experiências. CETESB - Palestra conferida. Disponível em: http:/www.mp.go.gov.br/portalweb/ hp/9/docs/palestra_dra._lucia.pdf. Acessado em: 10/06/2010.

Remondo J., Soto J., Gonzáles-Diéz A., Terán J.R.D., Cendrero A. 2005. Human impact on geomorphic processes and hazards in mountain areas in northern Spain. Geomorphology, 66(2005):69-84.

Rodrigues C. 2001. A teoria geossistêmica e sua contribuição aos estudos Geográficos e ambientais. Revista do Departamento de Geografia, 14(2001): 69-77.

Rodrigues C. 1997. Geomorfologia Aplicada: Avaliação de experiências e de instrumentos de planejamento físico-territorial e ambiental brasileiros. Tese de Doutorado em Geografia, Universidade de São Paulo, São Paulo, 279 p.

Rodrigues C. 2005. Morfologia original e morfologia antropogênica na definição de unidades espaciais de Planejamento Urbano: exemplo da metrópole paulista. Revista do Departamento de Geografia, 17(2005):101-111.

Simon A.L.H. 2007. A dinâmica de uso da terra e sua interferência na morfohidrografia da bacia do Arroio Santa Bárbara - Pelotas (RS). Dissertação de Mestrado em Geografia, Instituto de Geociências e Ciências Exatas, Universidade Estadual Paulista, Rio Claro, 185 p.

Simon A.L.H. \& Cunha C.M.L. 2008. Alterações geomorfológicas derivadas da intervenção de atividades antrópicas: Análise temporal na Bacia do Arroio Santa Bárbara - Pelotas (RS). Revista Brasileira de Geomorfologia, 9(2):29-38.

Tricart J. 1965. Principes etméthodes de la géomorphologie. Paris, Masson, 496 p.

Verstappen H.T. \& Zuidan R.A.V. 1975. ITC System of geomorphological survey. Manual ITC Textbook, Netherlands, Enschede, 52 p.

Vicente L.E. \& Perez Filho A. 2003. Abordagem sistêmica e geografia. Geografia, 28(8):232-344.

Vieira V.T. \& Cunha S.B. 2008. Mudanças na morfologia dos canais urbanos: Alto curso do rio Paquequer, Teresópolis - RJ (1997/98 - 2001). Revista Brasileira de Geomorfologia, 9(1):3-22.

Manuscrito ID 20521

Recebido em: 14/01/2011 Aprovado em: 10/07/2012 